\title{
Patrimonio Común de la Humanidad en la Antártica: imposibilidad de aplicación en el territorio por ausencia de sus características y principios esenciales ${ }^{1}$ \\ Common Heritage of Mankind in Antarctica: Impossibility of Application in the territory because of lack of its essential characteristics and principles
}

\author{
Giovannina Sutherland Condorelli \\ giovannina.sutherland@derecho.uchile.cl \\ Facultad de Derecho de la Universidad de Chile
}

Resumen: Se analiza el concepto de Patrimonio Común de la Humanidad y se revisa si los elementos esenciales del mismo se cumplen o no en la Antártica. Se pretende concluir si es o no posible dar tal categoría al Sexto Continente.

Palabras claves: Patrimonio Común de la Humanidad - Antártica

\begin{abstract}
The Common Heritage of Mankind concept is analyzed and it is reviewed if its essential elements are or not present in the Antarctic case. The paper tries to find if it is or not possible to give this category to the Sixth Continent.
\end{abstract}

Keywords: Common Heritage of Mankind - Antarctica

\section{Introducción}

La presente ponencia se basa en una investigación desarrollada a partir del año 2018 con motivo de la elaboración de la tesis de Licenciatura en Derecho en la Facultad de Derecho de la Universidad de Chile titulada "Antártica y Patrimonio Común de la Humanidad: inviabilidad

1 Ponencia presentada en las Jornadas Chilenas de Derecho Antártico 2019, Facultad de Derecho, Universidad de Chile, 28 de marzo del 2019. 
jurídica y desafíos geopolíticos”, que realicé en conjunto con Gisselle Gajardo, y bajo la dirección del Profesor Luis Valentín Ferrada.

No existe un consenso en la doctrina internacional en torno a la definición del Patrimonio Común de la Humanidad (en adelante, PCH), sin embargo, podemos circunscribirlo en dos ámbitos; uno referido a los bienes comunes o elementos compartidos por la comunidad internacional; y otro, al área de la cultura o de la protección del patrimonio cultural (Tello, 2012: 9). Este estudio responde al primero de ellos, pues nos encontramos en un contexto donde "el interés en torno al cambio climático, los océanos, la atmósfera, la Antártica y el espacio exterior, cobra cada vez más importancia en la literatura filosófico-ambiental, económica y políticojurídica bajo el significativo título de los global commons” (Míguez, 2014: 27).

Lo cierto es que es posible deducir las características propias del PCH a partir de los principios que rigen la regulación de los espacios tradicionalmente reconocidos como patrimonio común, es decir; a los fondos marinos en la Convención de las Naciones Unidas sobre el Derecho del Mar (1982, en vigor 1994), en adelante, CONVEMAR; y el espacio ultraterrestre en el Tratado sobre los Principios que deben regir las Actividades de los Estados en el Exploración y Utilización del Espacio Ultraterrestre, incluso la Luna y Otros Cuerpos Celestes (1966, en vigor 1967), en adelante, el Tratado del Espacio Ultraterrestre, y el Tratado de la Luna (1979, en vigor 1984).

\section{Características del Patrimonio Común de la Humanidad y su compatibilidad con la Antártica}

Previo a este estudio se han realizado compilaciones de algunas ideas sobre los principios rectores del PCH, como en los trabajos de la profesora María Luisa Tello, María Cecilia Añaños y el Dr. Rüdiger Wolfrum, sin embargo, no se ha intentado aplicar a la Antártica. Es por tanto nuestro objetivo identificar cuáles de estos elementos están o no presentes en el Sexto Continente y si estas eventuales carencias son o no esenciales para su calificación como PCH.

Para comprobarlo, analizaremos cada una de las características que se han definido como propias de los PCH. 


\subsection{Cooperación internacional}

Este principio consagra la interacción y trabajo conjunto de los Estados para la consecución de fines comunes. Establece la obligación de todos los Estados de cooperar internacionalmente en la exploración y el uso de los fondos marinos profundos y el fondo del océano, así como el espacio y sus cuerpos celestes (Wolfrum, 2009:5). Este principio asegura la unión de las partes en conformidad con el derecho internacional, con el interés de mantener de forma pacífica las relaciones diplomáticas y la ocupación de los espacios comunes, evitando perjudicar a los demás Estados con sus actos.

Esta idea rectora se aprecia en la regulación espacial, la cual se relaciona con la seguridad y el mantenimiento de la paz al promover la asistencia mutua y el intercambio en los avances conjuntos. Por ejemplo, el artículo 1 inciso final del Tratado del Espacio Ultraterrestre obliga a los Estados a facilitar y fomentar la cooperación internacional en las investigaciones relacionadas con los cuerpos celestes. De manera similar podemos reconocer la presencia de este principio en la Antártica.

\subsection{Administración internacional}

Tanto en la CONVEMAR con la Autoridad Internacional de los Fondos Marinos como en el Tratado del Espacio Ultraterrestre, se confiere control y administración a la Humanidad toda, reafirmando la idea de un interés común que debiese ser superior a los objetivos particulares de los Estados. Y en este sentido, la administración no la deben ejercen directamente éstos, sino que a través de órganos permanentes e independientes creados para tal fin. Debe tratarse de una estructura política que asegure el beneficio de cada una de las Partes a través de una organización que propenda a generar una relación de cooperación y solidaridad, y que cuente con estructura económica y social para su manejo sostenible. Como señala profesora María Cecilia Añaños (2014: 161), “debe tratarse de una acción colectiva autoorganizada, autorregulada y autoadministrada por los actores o usuarios mismos, estipulada mediante un acuerdo contractual y vinculante de cooperación”. De esta manera, como lo señala Wolfrum (2009:5): “Los Estados Partes deben actuar como una especie de fiducidiario en nombre de la Humanidad en su conjunto".

Blanc Altemir (1992: 216-17) considera que “este tipo de solución no sería aplicable a la Antártica ya que chocaría con otro grupo de intereses, en particular con los de las Partes Consultivas, cuyo peso en la comunidad internacional paralizaría cualquier tentativa de instaurar un régimen de internacionalización incompatible con el actual sistema de cooperación antártica".

Número de página no utilizable para citas 


\subsection{Exclusión de soberanía o Principio de no apropiación}

Cuando se quiere aplicar el concepto de $\mathrm{PCH}$ a un territorio es necesario que este no se encuentre sometido a la jurisdicción de ningún Estado, ni que se hayan constituido derechos soberanos por personas naturales o jurídicas con anterioridad, ya que dichas zonas y sus recursos no son susceptibles de apropiación. Por lo mismo, no se reconocerán las legislaciones internas que reivindiquen derechos soberanos en referencia a un bien que corresponda administrarse por todos. En ese sentido, Tello (2012: 25) señala que sería ilegítimo y pondría en riesgo la naturaleza del espacio declarado patrimonio común de la Humanidad.

Este principio se relaciona con la libertad de acceso y podemos encontrarlo por ejemplo en el artículo 137.1 de la CONVEMAR, que establece que ningún Estado podría reivindicar o ejercer soberanía o derechos soberanos sobre parte alguna de la Zona o sus recursos, ni ninguna persona natural o jurídica; y en el artículo 11 del Tratado de la Luna, al señalar que ni la superficie ni la subsuperficie de la Luna, ni ninguna de sus partes o recursos naturales podrán ser propiedad de ningún Estado, organización internacional intergubernamental o no gubernamental, organización nacional o entidad no gubernamental ni de ninguna persona fisica.

Como sabemos, en la Antártica es imposible la aplicación de este principio considerado esencial y rector del PCH, ya que históricamente se han reivindicado reclamaciones territoriales, sin perjuicio del estado en el que ellas se encuentran por la aplicación del artículo IV del Tratado Antártico.

\subsection{Utilización regulada}

Es de vital importancia para la estructuración de un sistema que imponga límites a las actuaciones de los Estado y de quienes estén bajo su control, por medio del cual se evite dañar los recursos valiosos que componen los espacios declarados como $\mathrm{PCH}$ y permitan su aprovechamiento para las próximas generaciones. Esta característica consiste por ende en una necesaria consagración de un régimen jurídico que establezca la responsabilidad internacional de los Estados por los daños que puedan generar sus actividades a través de agentes nacionales u organizaciones no estatales bajo su jurisdicción. Asimismo, y en concordancia con el principio de uso pacífico, debe promoverse la prohibición de hostilidades y evitarse las amenazas o cualquier uso de la fuerza que pueda implicar el quiebre del equilibrio pacífico entre los Estados.

Mediante la utilización regulada se debe hacer efectivo el derecho a la libertad e igualdad en el acceso y uso del bien común para su explotación e investigación científica, equiparando las

Número de página no utilizable para citas 
condiciones de las partes en las garantías de la gestión compartida. Según esto, la regulación del espacio ultraterrestre hace efectiva la no discriminación en el derecho de los Estados a acceder a la órbita superior, en el entendido de que el único impedimento es la disponibilidad de recursos e implementos tecnológicos que tenga cada uno para el desarrollo de investigación y exploración. Por ejemplo, a través del artículo $6 \mathrm{~N}^{\circ} 1$ del Tratado de la Luna y el artículo 1 inciso 2 del Tratado del Espacio Ultraterrestre se consagra que la investigación cientifica en la Luna y los cuerpos celestes será libre para todos los Estados Partes, sin discriminación de ninguna clase, sobre la base de la igualdad y de conformidad con el derecho internacional. Por su parte, sí es posible encontrar esta regulación en el continente austral a través del Sistema del Tratado Antártico (en adelante, STA) y sus Reuniones Consultivas.

Ahora bien, es necesario criticar que a pesar de que estos sean ideales en la administración, no se debe olvidar que los territorios declarados PCH son inhóspitos y de difícil acceso, por lo que se genera una controversia al existir un beneficio únicamente para los Estados con suficiente soporte financiero y capacidad tecnológica, en desmedro de aquellas naciones en vías de desarrollo con deficiente cantidad de recursos. Por lo anterior es que se insta a que en estos espacios comunes la exploración e investigación realizada beneficie a toda la comunidad internacional.

\subsection{Efecto distributivo}

Para ver la aplicación de este principio, previamente debemos distinguir dos tipos de beneficios que ofrecen los bienes comunes: por una parte, uno inmaterial que trata sobre el conocimiento que se genera a través de la investigación de los territorios y sus recursos, y por otra, el beneficio material respecto del uso físico del lugar y la posible extracción de los recursos que contenga. En ambas situaciones se intenta establecer una justicia equitativa para los Estados, que se extienda más allá del principio de la libertad de acceso, en consideración a que los recursos son compartidos y debe preservarse el interés de un derecho igualitario. En ese sentido, se establece en el Anexo de la Declaración sobre la Cooperación Internacional en la Exploración y Utilización del Espacio Ultraterrestre que, en beneficio de todos los Estados, las naciones pueden determinar libremente todos los aspectos de su participación en la cooperación internacional en la exploración y utilización del espacio ultraterrestre sobre una base equitativa y mutuamente aceptable.

Actualmente no es posible aplicar estos ideales de igualdad en la Antártica, pues existe una participación diferenciada de los Estados en el poder de decisión dentro de las Reuniones Consultivas, con presencia permanente en el territorio y desarrollo de actividades científicas tan 
solo para las Partes Consultivas. Por ende, los beneficios obtenidos de la investigación no son para la Humanidad en su conjunto.

Consecuencia de esta discusión se sostiene que los recursos de uso común enfrentan serios problemas de sobreuso y presentan el dilema del free rider (Añaños, 2014: 160). El sobreuso, por una parte, puede llevar a la destrucción del bien común o a su agotamiento si se llega a tratar de un recurso no renovable, mientras que el problema del polizón se configura cuando el uso de ciertos miembros de la administración sobrepasa el de los demás y les excluye del mismo, evitando el reparto equitativo.

\subsection{Dimensión inter-temporal}

Como sabemos, la beneficiaria de los bienes comunes es finalmente la Humanidad, sin embargo, es necesario generar discusión respecto a quienes consideramos dentro de su definición. Wolfrum (2009: 6), nos indica que el interés de futuras generaciones tiene que ser respectado al hacer uso de los bienes comunes internacionales, mientras que Tello (2012: 28), agrega que "el término Humanidad no alude solamente a las generaciones actuales sino a la especie humana sin límites temporales de existencia y, por tanto, incluye a las futuras (...) y la gestión de dichos recursos debe ser racional sin que ocasione el agotamiento de los recursos o cause daños al medioambiente, conforme el principio de desarrollo sostenible.

De este elemento se deriva otro principio transversal a la línea temporal de explotación que es de vital importancia: la sustentabilidad de los recursos. Por este motivo es que anteriormente se destacó la necesidad de establecer un régimen de responsabilidad para evitar daños a corto y largo plazo a raíz de la sobreexplotación o poca prevención.

Es posible deducir este principio en la regulación del STA, ya que existe una constante preocupación por su ecosistema y perduración a través del tiempo. Un ejemplo claro es a través del Protocolo del Tratado Antártico sobre Protección al Medio Ambiente (1992, en vigor 1998), mediante el cual se previene la contaminación marina, se gestionan y protegen zonas en peligro, entre otros elementos que propenden a una conservación de la flora y fauna en miras del futuro y sus generaciones.

\subsection{Uso pacífico}

El sentido de este principio es que las áreas comunes sean utilizadas en conjunto sin poner en riesgo la cosa común, asegurando el acceso equitativo a todos los Estados beneficiados. Esto a su vez se relaciona con el principio de no militarización de los espacios, para evitar que lleguen

Número de página no utilizable para citas




a ser motivo de conflictos internacionales que puedan devenir eventualmente en la constante histórica de querer apropiarse de los territorios. Algunas de sus consagraciones las encontramos en el artículo IV del Tratado del Espacio Ultraterrestre al emplazar a no colocar en órbita alrededor de la Tierra ningún objeto portador de armas nucleares o de destrucción en masa; y en el artículo 301 de la CONVEMAR, que prohíbe a sus Estados Partes recurrir a la amenaza o uso de la fuerza contra la integridad territorial o la independencia política de cualquier Estado, para ejercer sus derechos o cumplir obligaciones.

A modo de síntesis, si intentamos aplicar los principios del PCH a la Antártica, solo es posible que cuatro de ellos coincidan, los cuales son: uso pacífico; dimensión inter-temporal; utilización regulada; y cooperación internacional. Mientras que, por otro lado, no guardan en común la esencia de un efecto distributivo; administración internacional, ni la más importante que es la exclusión de soberanía.

En las últimas décadas, se ha discutido (Villamizar, 2016; Sepúlveda, 2018) la idea de que este territorio sea un bien común que beneficie a todas las personas pues se proyecta que en el futuro sus recursos serán aún más valiosos por la escasez de agua y alimentos en el resto del mundo. Sin embargo, la Antártica carece de elementos fundamentales para circunscribirse en la noción de PCH, ya que existe una manifiesta ausencia de interés por parte de los Estados de abandonar el régimen vigente y el principio de apropiación.

\section{Referencias bibliográficas}

AÑaños MeZA, María Cecilia. "La idea de los bienes comunes en el sistema internacional: ¿Renacimiento o extinción?”, Anuario Mexicano de Derecho Internacional, 14 (2014): 153-195.

Blanc Altemir, Antonio. El patrimonio común de la humanidad. Hacia un régimen jurídico internacional para su gestión. (Barcelona: BOSCH, Casa Editorial, S.A, 1992).

MíguEZ NúÑEZ, Rodrigo. De las cosas comunes a todos los hombres, notas para un debate. Revista Chilena de Derecho, 41 (2014): 7-36.

SEPÚlveda COX, Jaime. "Importancia geopolítica del continente antártico”. Revismar, 6 (2018): 524-535. 
Patrimonio Común de la Humanidad en la Antártica

Giovanna Sutherland Condorelli

Tello Moreno, Luisa Fernanda. El derecho al patrimonio común de la Humanidad: Origen del derecho de dcceso al patrimonio cultural y su disfrute. (México: Comisión Nacional de los Derechos Humanos, 2012).

Wolfrum, Rüdiger. "Common Heritage of Mankind". En Max Planck Encyclopedia of Public International Law. Oxford Public International Law, 2009.

ViLlamiZAR LAMUS, Fernando. "Las necesidades mundiales de agua y la Antártida como reserva natural: ¿Puede explotarse el agua antártica?”, Revista de Relaciones Internacionales, Estrategia y Seguridad. 11 (2016): 75-92. 